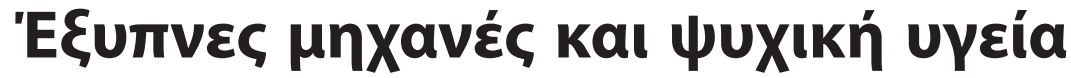

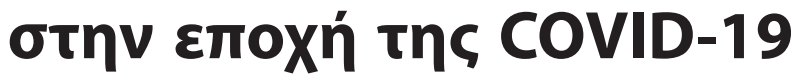

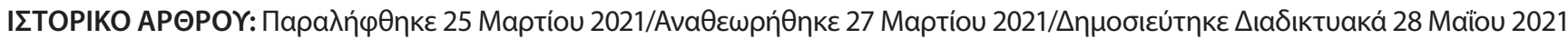

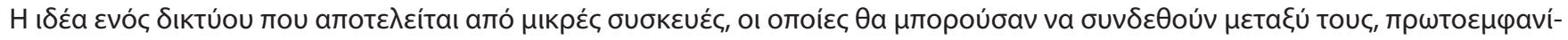

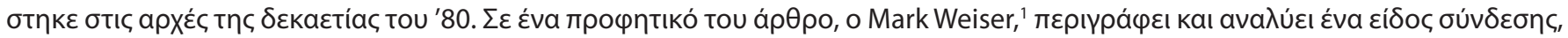

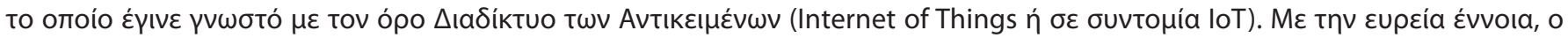

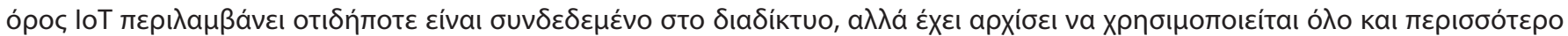

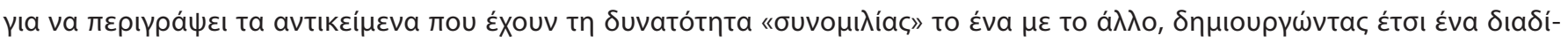

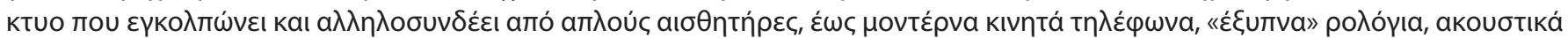

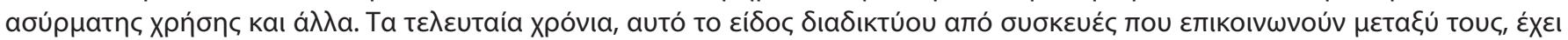

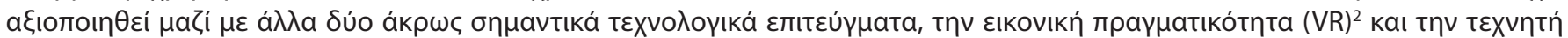

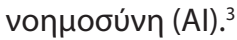

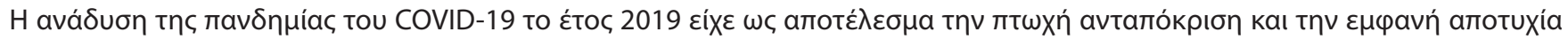

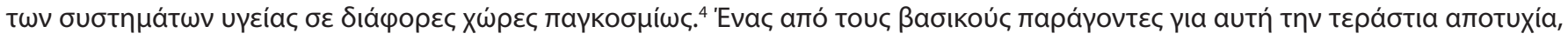

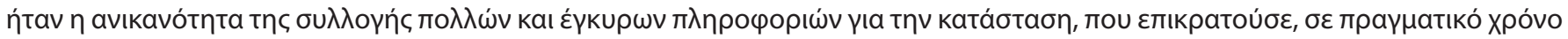

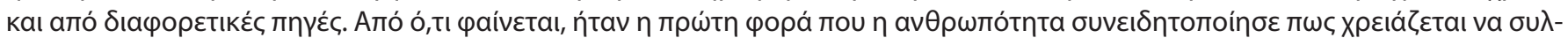

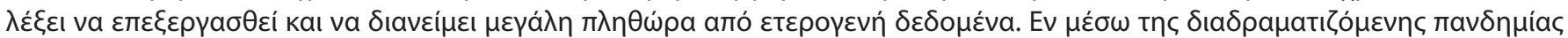

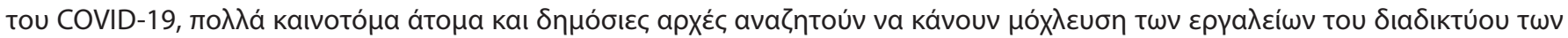

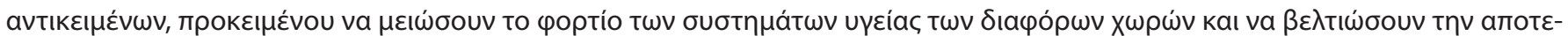

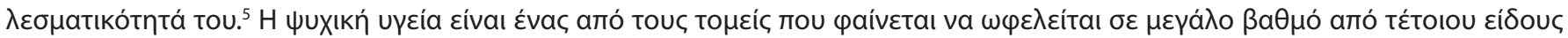

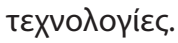

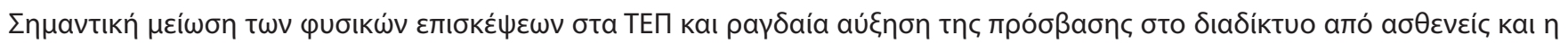

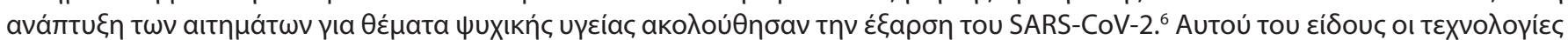

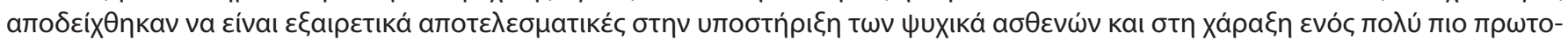

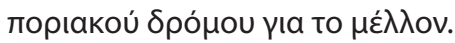

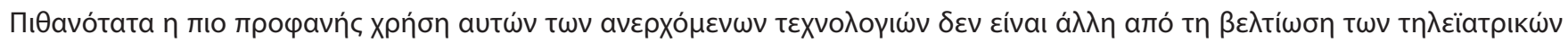

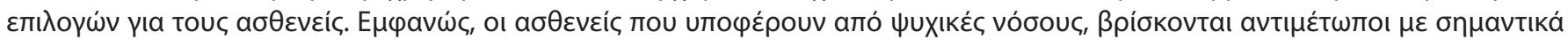

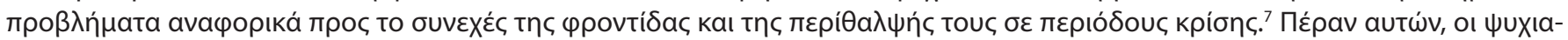

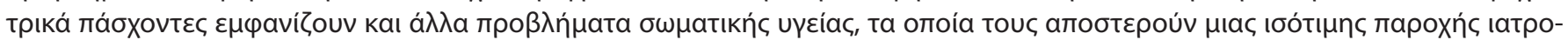

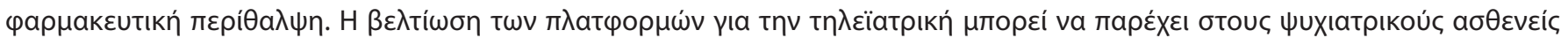

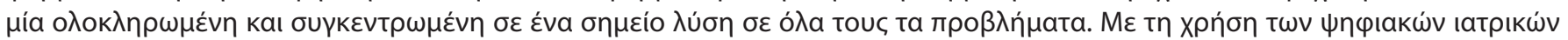

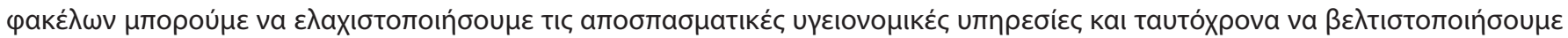

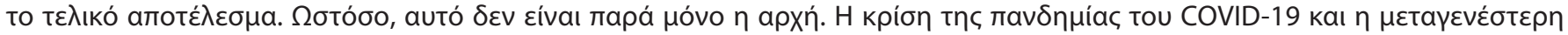

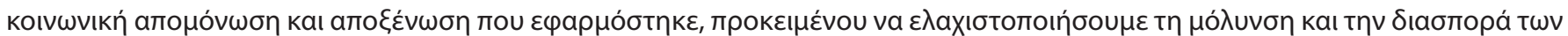

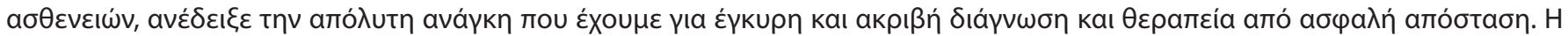

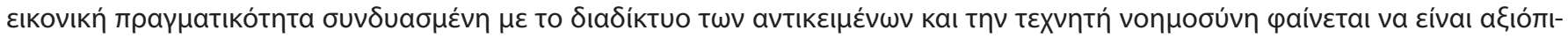

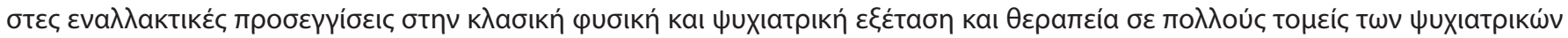

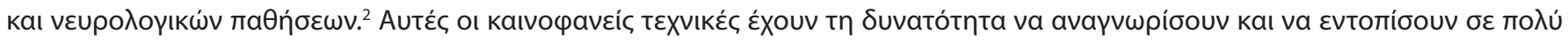

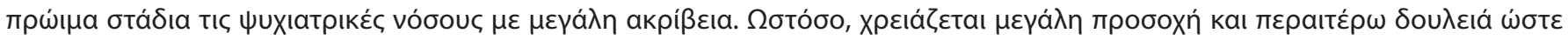

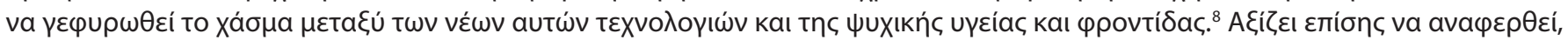

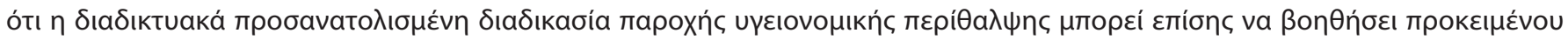

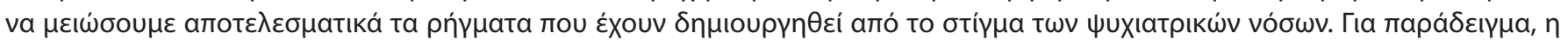

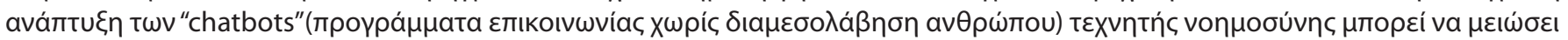

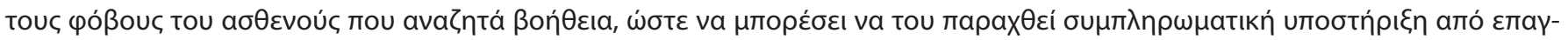

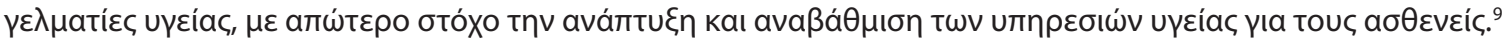




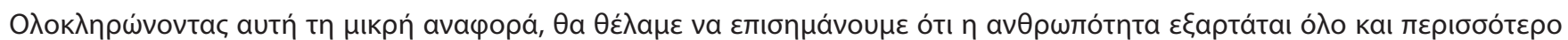

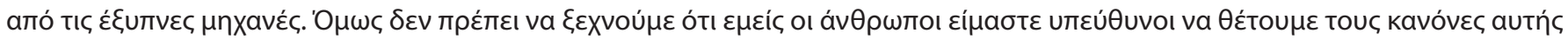

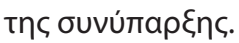

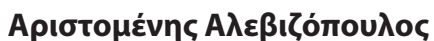

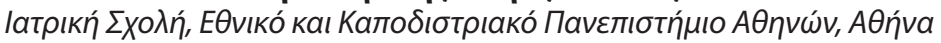 \\ lákwßoc Kpnтıкós \\ Department of Bioengineering, Imperial College London, South Kensington Campus, London, UK

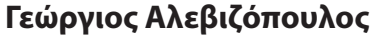

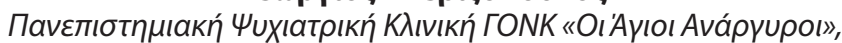

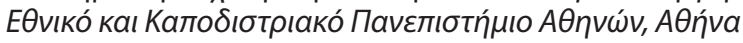

\section{BıBAtoypacpía}

1. Weiser M. The Computer for the 21st Century. Scientific Am 1991, 265: 94-104

2. Kritikos J, Alevizopoulos G, Koutsouris D. Personalized Virtual Reality Human-Computer Interaction for Psychiatric and Neurological Illnesses: A Dynamically Adaptive Virtual Reality Environment That Changes According to Real-Time Feedback from Electrophysiological Signal Responses. Front Hum Neurosci 2021, 15:596980, doi: 10.3389/ fnhum.2021.596980

3. Fulmer R, Joerin A, Gentile B, Lakerink L, Rauws M. Using Psychological Artificial Intelligence (Tess) to Relieve Symptoms of Depression and Anxiety: Randomized Controlled Trial. JMIR Ment Health 2018, 5:e64, doi:10.2196/mental.9782

4. Liapis C, Alevizopoulos G. Leadership in Covid-19 Era: From Hubris to Political Post-Traumatic Stress. J Psychiatry Behav Sci 2021, 4:1053
5. Chamola V, Hassija V, Gupta V, Guizani M. A Comprehensive Review of the COVID-19 Pandemic and the Role of IoT, Drones, Al, Blockchain, and 5 G in Managing Its Impact. IEEE Access 2020, 8:90225-90265, doi: 10.1109/ACCESS.2020.2992341

6. Galea S, Merchant RM, Lurie N. The Mental Health Consequences of COVID-19 and Physical Distancing: The Need for Prevention and Early Intervention. JAMA Intern Med 2020, 180:817-818, doi: 10.1001/jamainternmed.2020.1562

7. Alevizopoulos G, Nystazaki M. Long Acting Injectable Antipsychotics: Ongoing use during the COVID-19 pandemic and successful use of internet-based support in Greece. Eur J Psychiatry 2021, In press.

8. Gunter TD, Terry NP. The emergence of national electronic health record architectures in the United States and Australia: models, costs, and questions. J Med Internet Res 2005, 7:e3, doi:10.2196/jmir.7.1.e3

9. Graham S, Depp C, Lee EE, Nebeker C, Tu X, Kim HC, Jeste DV. Artificial Intelligence for Mental Health and Mental Illnesses: an Overview. Curr Psychiatry Rep 2019, 21:116, doi:10.1007/s11920-019-1094-0 


\title{
Intelligent machines and mental health in the era of COVID-19
}

\author{
ARTICLE HISTORY: Received 25 March 2021/Revised 27 March 2021/Published Online 28 May 2021
}

The idea of a network of small devices that would be able to connect each other, appeared in the early 80 s. In a prophetic article, Mark Weiser, ${ }^{1}$ described such a connection, that it is now known under the term of Internet of Things (loT). In a broadest sense, the term loT encompasses everything connected to the internet, but it is increasingly being used to define objects that "talk" to each other, creating a network from simple sensors to smartphones and wearables connected. During the recent years this network of communicating devices has been combined with other technological achievements, and particularly with the Virtual Reality $(\mathrm{VR})^{2}$ and the Artificial Intelligence (AI). ${ }^{3}$

The emerge of COVID-19 pandemic in 2019, resulted to the poor response and healthcare failures of many countries globally. ${ }^{4}$ One of the main reasons for such a failure, was the inability of accurate data collection from different sources. Apparently, it was the first time, humanity realized the need for massive amounts of heterogeneous data to be collected, interpreted, and shared. Amid the ongoing COVID-19 pandemic, several innovators and public authorities are looking to leverage loT tools to reduce the burden on the healthcare systems. ${ }^{5}$ Mental health is one of the areas that seems to benefit the most by such technologies.

A significant decrease of the total amount of ER visits and a dramatic increase of internet access from the patients and care givers along to the development of applications for mental health issues, followed the outbreak of SARS-CoV-2. ${ }^{6}$ Such technologies proved to be efficient to help mentally ill patients and pioneer the path in the future.

Probably the most obvious use of these emerged technologies is the improvement of the telehealth options. Patients who suffer from mental illness face significant problems towards the continuity of care during the crisis. ${ }^{7}$ Nonetheless, they usually have other health problems, that deprive them from an equitable health care provision. Improved telehealth platforms can give them a single point access to address all their problems. The use of electronic health records can reduce the fragmentary health services and improve the outcome. ${ }^{8}$ However, this is only the beginning. The COVID-19 crisis and the subsequent social isolation, to reduce both the contamination and the spread of the disease, highlighted the necessity for providing accurate and secure diagnoses and treatments from a safe distance. Virtual reality combined with loT and Al technologies seems to be a reliable alternative to the classic physical and mental examination and treatment in many areas of mental and neurological diseases. ${ }^{2}$ These novel techniques can spot the early signs and detect mental illnesses with high accuracy. However, caution and more work are required to bridge the space between these recently thrived, technologies and mental health care. ${ }^{7}$ It is worth mentioning, that internet-oriented health care procedures can also help to reduce the gaps caused by the stigma of mental illness. For example, the development of Al chatbots (an application used to chat directly with a human) can alleviate the fears of judgment of the help seeking persons and provide the professionals with a supplemental support toward improved services to their patients. ${ }^{9}$

A final remark for conclusion. Humanity is more and more depended to the "intelligent" machines. However, we must not forget that we humans are responsible to set the rules of such a co-existence.

Aristomenis Alevizopoulos

School of Medicine, National and Kapodistrian University of Athens, Greece

Jacob Kritikos

Department of Bioengineering, Imperial College London, South Kensington Campus, London, United Kingdom

\section{Georgios Alevizopoulos}

Department of Psychiatry, Agioi Anargyroi Hospital, National and Kapodistrian University of Athens, Greece 


\section{References}

1. Weiser M. The Computer for the 21st Century. Scientific Am 1991, 265 : 94-104

2. Kritikos J, Alevizopoulos G, Koutsouris D. Personalized Virtual Reality Human-Computer Interaction for Psychiatric and Neurological Illnesses: A Dynamically Adaptive Virtual Reality Environment That Changes According to Real-Time Feedback from Electrophysiological Signal Responses. Front Hum Neurosci 2021, 15:596980, doi: 10.3389/ fnhum.2021.596980

3. Fulmer R, Joerin A, Gentile B, Lakerink L, Rauws M. Using Psychological Artificial Intelligence (Tess) to Relieve Symptoms of Depression and Anxiety: Randomized Controlled Trial. JMIR Ment Health 2018, 5:e64, doi:10.2196/mental.9782

4. Liapis C, Alevizopoulos G. Leadership in Covid-19 Era: From Hubris to Political Post-Traumatic Stress. J Psychiatry Behav Sci 2021, 4:1053
5. Chamola V, Hassija V, Gupta V, Guizani M. A Comprehensive Review of the COVID-19 Pandemic and the Role of IoT, Drones, Al, Blockchain, and 5 G in Managing Its Impact. IEEE Access 2020, 8:90225-90265, doi: 10.1109/ACCESS.2020.2992341

6. Galea S, Merchant RM, Lurie N. The Mental Health Consequences of COVID-19 and Physical Distancing: The Need for Prevention and Early Intervention. JAMA Intern Med 2020, 180:817-818, doi: 10.1001/jamainternmed.2020.1562

7. Alevizopoulos G, Nystazaki M. Long Acting Injectable Antipsychotics: Ongoing use during the COVID-19 pandemic and successful use of internet-based support in Greece. Eur J Psychiatry 2021, In press

8. Gunter TD, Terry NP. The emergence of national electronic health record architectures in the United States and Australia: models, costs, and questions. J Med Internet Res 2005, 7:e3, doi:10.2196/jmir.7.1.e3

9. Graham S, Depp C, Lee EE, Nebeker C, Tu X, Kim HC, Jeste DV. Artificial Intelligence for Mental Health and Mental Illnesses: an Overview. Curr Psychiatry Rep 2019, 21:116, doi:10.1007/s11920-019-1094-0 